\title{
APORTE DEL US DOPPLER COLOR DE ALTA RESOLUCION EN LA EVALUACION PRE Y POSTOPERATORIA EN CIRUGIA DE COLGAJOS
}

\section{Dr. Patricio Azócar G.}

Servicio Imagenología Hospital del Trabajador. Santiago

Abstract: The article review the role of the Doppler ultrasound in the evaluation of patients with tissue transfer or tissue transplantation surgical techniques. Key words: Doppler ultrasound, Tissue transplantation surgery.

Resumen: Se efectúa descripción de las técnicas de cirugías de colgajos, de las implicancias de la circulación cutánea en el éxito de estas cirugías y aporte del ultrasonido Doppler color de alta resolución como método de estudio vascular no invasivo, en la evaluación pre y postoperatoria.

Palabras claves: Cirugía colgajo, Ultrasonido Doppler.

\section{Introducción}

Algunas lesiones traumáticas de alta energía pueden causar pérdida de grandes superficies en las partes blandas de extremidades y pueden ser provocadas, en forma directa, con pérdida inmediata de ellas o en forma indirecta y más tardía a través de un compromiso vascular o infeccioso.

La cirugía de colgajos es la técnica usada para la cobertura de estas extensas soluciones de continuidad, que comprometan piel, celular subcutáneo y planos musculares.

Cuando existe pérdida y amputación traumática de los dedos de la mano es posible su reimplante en forma inmediata o en forma programada para recuperar la función de la extremidad, realizando trasplante autólogo de un dedo del pie a la mano, lo que es llamado cirugía de transposición.

El estudio preoperatorio de todas estas cirugías es necesario para su planificación y la

Azócar P. Aporte del uso Doppler color de alta resolución en la evaluación pre y post operatoria en cirugía de colgajos. Rev Chil Radiol 2005; 11: 51-57.

Correspondencia: Dr. Patricio Azócar G.

E-mail:pazocar@tie.cl evaluación del estado de los pedículos vasculares, tanto del sitio donante como del receptor, es fundamental. Se revisan el rol y aporte del ultrasonido (US) Doppler color de alta resolución como método de estudio vascular no invasivo.

\section{Anatomía vascular de piel y fascias}

Es importante conocer adecuadamente la anatomía vascular de la piel, fascia y músculo en las regiones de interés. El defecto a reparar debe ser cubierto con tejidos resistentes y duraderos, lo que dependerá de un aporte vascular adecuado.

Piel: La irrigación cutánea depende de grandes troncos arteriales que perforan las aponeurosis y el celular subcutáneo formando una rica red arterial. Es necesario que se conserve al menos una pequeña fracción de la irrigación cutánea para mantener la viabilidad de la piel, siendo el factor más importante para asegurar un colgajo viable.

La epidermis es un espacio avascular que se nutre por imbibición de los vasos dérmicos que se proyectan a través de las papilas. La vascularización dérmica puede dividirse en forma esquemática en dos grandes grupos, los vasos cutáneos directos y los indirectos, formados a su vez por los vasos perforantes músculo-cutáneos del sistema fasciocutáneo (Figura 1).

Celular subcutáneo: Tiene su propio sistema vascular. Los septos fibrosos conectan la dermis a la fascia profunda y a través de ellos pasan los vasos cutáneos que provienen de esta última y dan ramas a este tejido. En las zonas donde la capa grasa del celular subcutáneo es delgada la irrigación se efectúa a través de ramas descendentes del plexo subdérmico.

Fascia profunda: En el tronco la vascularización es una red bien desarrollada sobre el plano muscular, es elástica y permite los movimientos en tórax y abdomen.

En las extremidades los vasos circulan a través de los septos fasciales entre los planos musculares. 

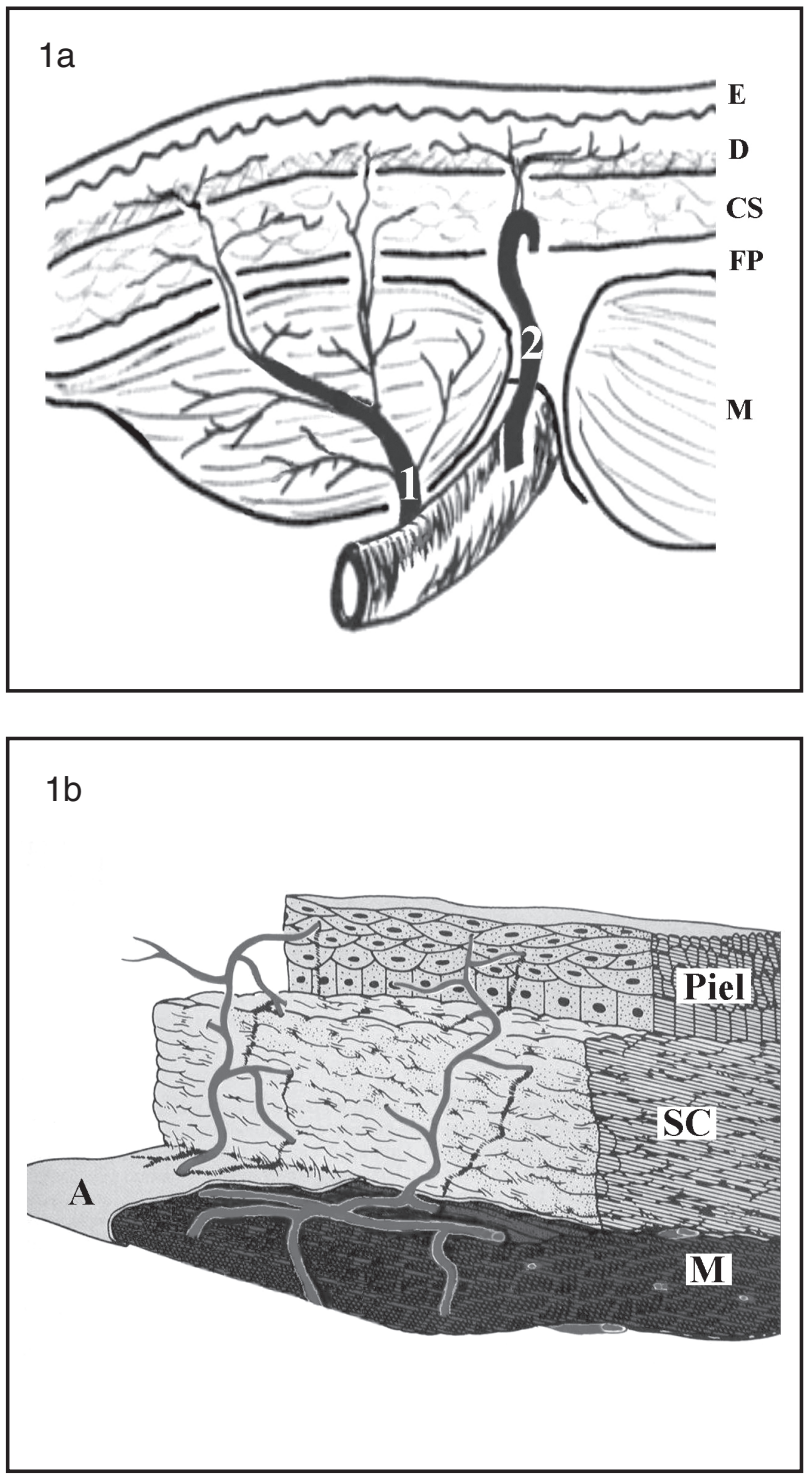

Figura 1 a,b. a) Esquema representando la circulación cutánea. b) Representación de los troncos arteriales que perforan la aponeurosis para alcanzar la piel. 1: Arteria cutánea indirecta. 2: Arteria cutánea directa. E: Epidermis. D: Dermis. SC: Tejido celular subcutáneo. M: Músculo. A: Aponeurosis.

\section{Clasificación de los colgajos}

Se define como colgajo la técnica quirúrgica en donde el segmento anatómico trasladado lleva consigo aporte vascular, a diferencia del injerto, que no lo lleva. Se pueden clasificar en dos formas: A) Según composición del tejido transferido, y B) Según vascularización.

A1. Colgajo cutáneo: Compuesto por piel y tejido celular subcutáneo. Tiene un pedículo vascular, que lo mantiene unido a las estructuras profundas. El pedículo del colgajo es un puente cutáneo que vasculariza directamente la piel del colgajo.
A2. Colgajo fascio-cutáneo: Compuesto por un plano cutáneo y aponeurótico. El aporte vascular consiste en perforantes que suben a la superficie cutánea a través de los septos fasciales, entre los planos musculares, y que forman un plexo en la fascia profunda para irrigar el tejido celular subcutáneo y la dermis.

A3. Colgajo músculo-cutáneo: Compuesto por músculo y por una porción cutánea, su irrigación es por arterias perforantes musculares que atraviesan la fascia y se distribuyen en el celular subcutáneo.

B. Colgajo perforante: Durante los últimos años ha surgido un interés especial por disminuir la morbilidad de la zona donante, lo que sumado a los avances en las descripciones anatómicas de la vascularización de la piel y fascia ha hecho posible el desarrollo de este tipo de colgajos.

Ellos se basan en arterias que atraviesan la fascia y/o el músculo como vía para alcanzar la piel. Representan una nueva alternativa en la escala reconstructiva, ya que ofrecen al paciente la cobertura requerida, junto con una disminución importante en la morbilidad de la zona donante, debido a la preservación de la función muscular.

\section{Estudio Doppler color en cirugía de colgajos}

Se debe contar con un equipo de US de alta resolución y transductores de $5 \mathrm{a} 15 \mathrm{MHz}$, para evaluar el estado del pedículo vascular

Técnica: Previo al examen debemos revisar la anatomía vascular de la zona donante y receptora, como también conocer la técnica quirúrgica a utilizar.

Es ideal efectuar los estudios en presencia del cirujano, quien nos indicará los puntos de interés que debemos chequear, además de efectuar marcas en la piel para identificar perforantes y otros reparos anatómicos fijos.

Si se detectan anomalías vasculares tales como oclusión o hipoplasia de un segmento arterial, la técnica quirúrgica variará y se deben evaluar otros pedículos vasculares alternativos. Ante la presencia de variantes de recorrido debemos efectuar siempre estudios comparativos.

Durante el estudio se deben obtener registros del calibre del vaso, características de sus paredes, permeabilidad, ubicación, variantes de recorrido y dominancia de flujo, del vaso arterial y venoso de la zona donante y del área receptora. También se determina la presencia y número de perforantes cutáneas, marcando en la piel su ubicación.

En el control postquirúrgico se evalúa la permeabilidad del vaso arterial y venoso anastomosado en búsqueda de complicaciones tales como trombosis, estenosis y presencia de colecciones. 


\section{Anatomía particular de algunos vasos usados en cirugía de colgajos}

A continuación se describen detalles anatómicos de los vasos arteriales más frecuentemente evaluados en cirugía de colgajos.

Colgajo de músculo recto abdominal: Está basado en perforantes que atraviesan el músculo recto abdominal; son ramas de la arteria epigástrica inferior profunda, que a la vez es rama de la ilíaca externa (Figura 2).

La epigástrica después de su origen se dirige hacia el ombligo y penetra el músculo recto abdominal en su borde lateral. Se divide en ramas lateral y medial, las que tienen aproximadamente el mismo calibre, aunque en algunos individuos la lateral tiene mayor diámetro y es la que se anastomosa con el sistema de la arteria epigástrica superior(2).

La arteria epigástrica inferior profunda presenta un pedículo arterial de $7 \mathrm{~cm}$ de longitud; su calibre al igual que la vena acompañante es de 3 $\mathrm{mm}$.

Colgajo perforante de arteria glútea superior: Las arterias perforantes atraviesan el músculo glúteo mayor para alcanzar la piel y provienen de la arteria glútea superior, rama de la ilíaca interna. Las perforantes músculocutáneas se localizan principalmente en la región supero-lateral del músculo y sólo se deben incluir las que se encuentran por encima del músculo piriforme ${ }^{(2)}$

Colgajo antero-lateral de muslo: Está basado en las arterias que perforan el músculo vasto lateral (Figuras 3, 4). Las arterias perforantes pueden originarse en la rama descendente o en la rama transversal de la arteria circunfleja lateral; como también en la arteria femoral profunda ${ }^{(1,2)}$.

La arteria femoral circunfleja lateral presenta un pedículo arterial de $8-12 \mathrm{~cm}$ de longitud y su calibre es de $2,1 \mathrm{~mm}$, y el de la vena acompañante 2,3 $\mathrm{mm}$.

Colgajo homodigital invertido: Usado para cobertura de partes blandas de la falange distal, cuando existe exposición ósea, siendo una cirugía reconstructiva y una alternativa que evita la amputación. Requiere indemnidad del segundo arco anastomótico de Edwards.

Se debe evaluar la permeabilidad de las arterias intermetacarpianas dorsales, las arterias digitales y la del segundo arco anastomótico de Edwards ${ }^{(5)}$.

La primera arteria intermetacarpiana dorsal, rama terminal de la arteria radial, puede efectuar su recorrido, por el plano superficial del primer espacio interóseo, entre o por debajo de los planos musculares. El diámetro de esta arteria es de 1 a $1,5 \mathrm{~mm}$ y su longitud es de 4 a $8 \mathrm{~mm}$.
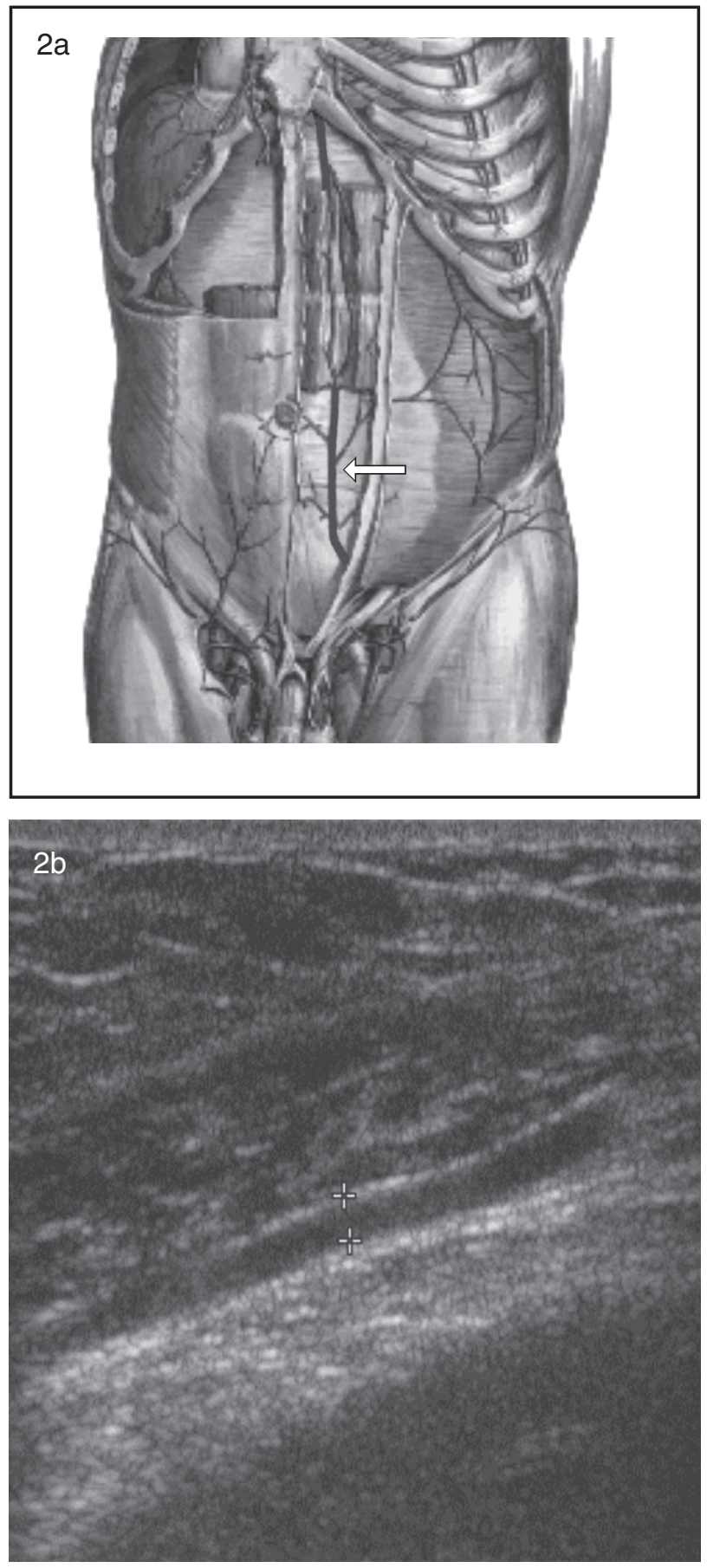

Figura 2 a-e. a) Esquema que representa la ubicación anatómica de la arteria epigástrica inferior profunda (flecha). b) Ecografía modo B, vista longitudinal, de la arteria epigástrica inferior profunda con un calibre de 2,1 $\mathrm{mm}$ (entre signos +). c) Vista longitudinal, de la arteria epigástrica inferior profunda, demostrando su permeabilidad. d) Ecografía Doppler color, vista transversal, de las arterias (en rojo) y venas (en azul) epigástricas inferiores profundas, situadas hacia el borde lateral distal del músculo recto abdominal. e) Cirugía de colgajo del recto abdominal, en fase de cicatrización, con cobertura exitosa de una extensa lesión de la parte distal de la pierna. 

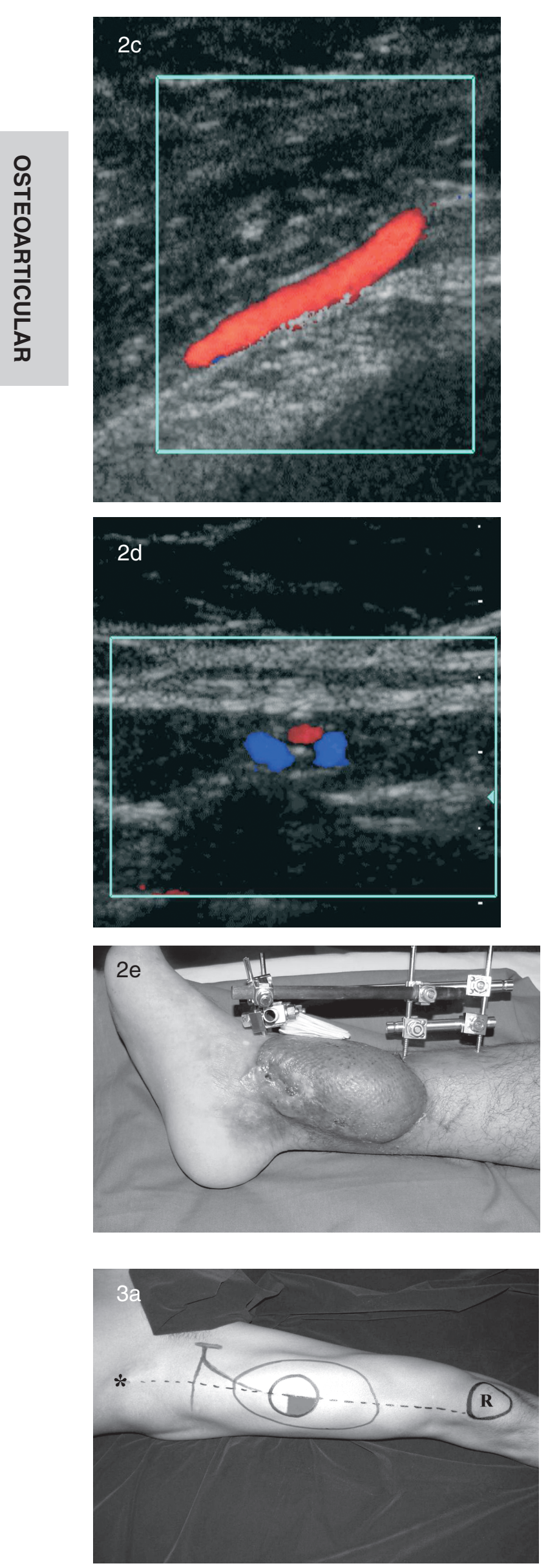

Figura 3 a-c: a: Colgajo del territorio ubicado entre una horizontal que pasa por el trocánter mayor y una línea paralela a la anterior por encima de la rótula. El límite medial es la línea media del muslo y el lateral se encuentra sobre el tabique intermuscular, ubicación de perforantes septo-cutáneas en el cuadrante inferoexterno de la zona demarcada con el círculo menor. b,c: Ecografía Doppler color, de ramos septo-cutáneos de la arteria femoral circunfleja lateral vista longitudinal (flecha en b) y vista transversal (rojo en c). VL: Vasto Lateral, RF: Recto Femoral, I: Tabique intermuscular.
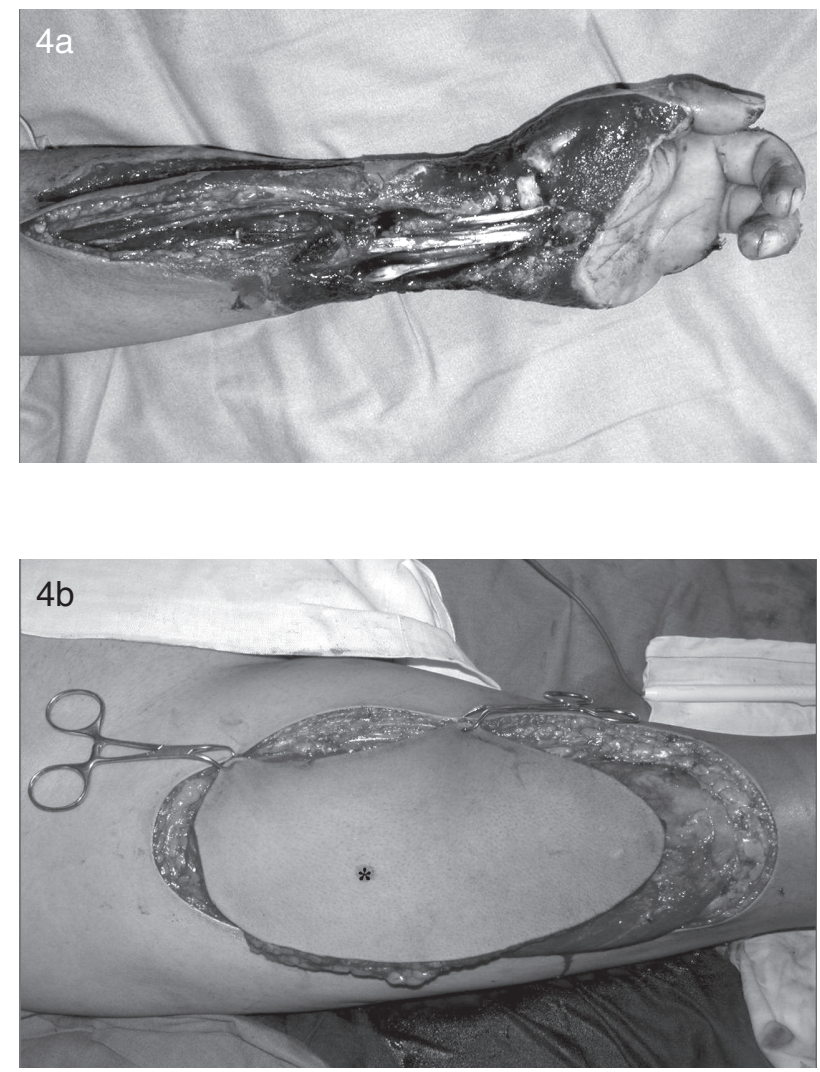

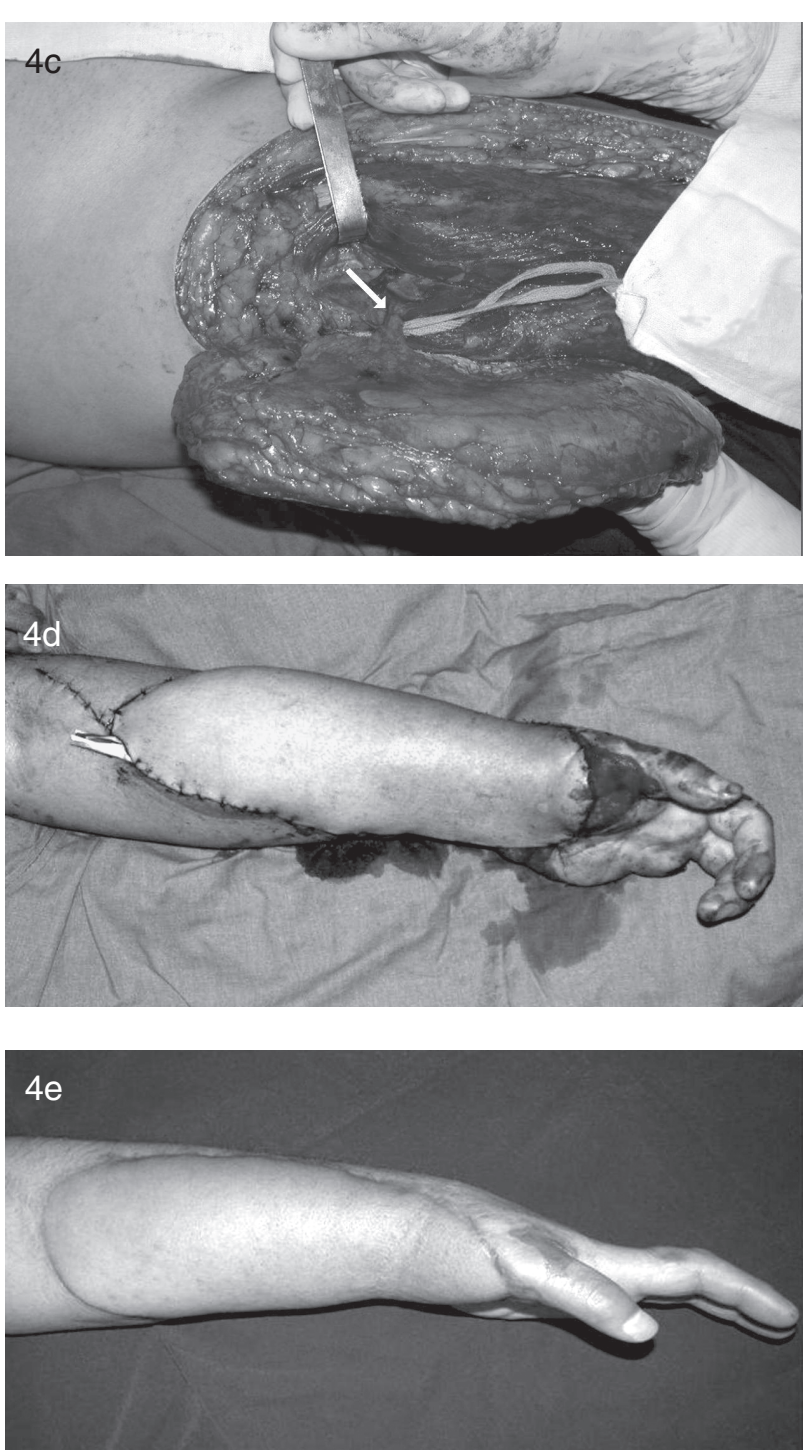

Figura 4 a-e. Desforramiento del antebrazo en su cara flexora. a) Extensa lesión de partes blandas con exposición de tendones y pérdida de los dedos anular y meñique. b,c) Colgajo anterolateral de muslo. Disección con marca en la piel de la ubicación de ramas perforantes cutáneas (asterisco en b). Disección del pedículo vascular de ramas perforantes septo-cutáneas (flecha en c). d) Cobertura de antebrazo con colgajo antero lateral de muslo. e) Control alejado, con excelente cobertura cutánea, conservación de la función del antebrazo y de gran parte de la función de la mano.

Transferencia parcial de primer ortejo: En ella, a nivel de la zona dadora se debe evaluar la primera arteria intermetatarsiana dorsal, que es rama terminal de la arteria pedia y que puede efectuar su recorrido por el plano superficial del primer espacio interóseo, entre los planos musculares o por debajo de éstos ${ }^{(3)}$. Su diámetro es de 1,2 a 1,5 mm y su longitud de 4 a 12 mm (Figura 5).

Esta técnica es usada para la reconstrucción de los dedos pulgares en casos de su amputación, permite recobrar gran parte de la función de la mano, recuperando la función de pinza (Figura 6).

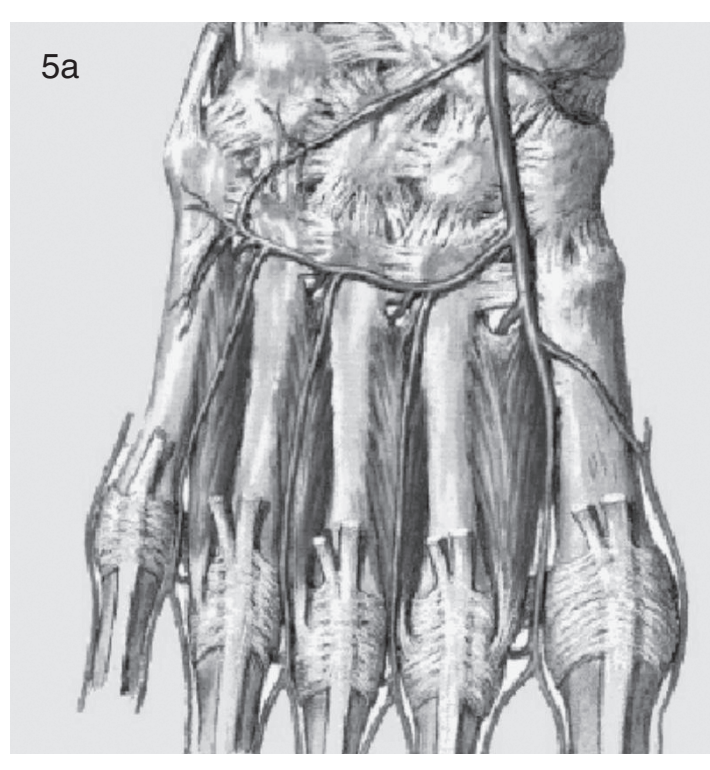

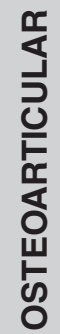
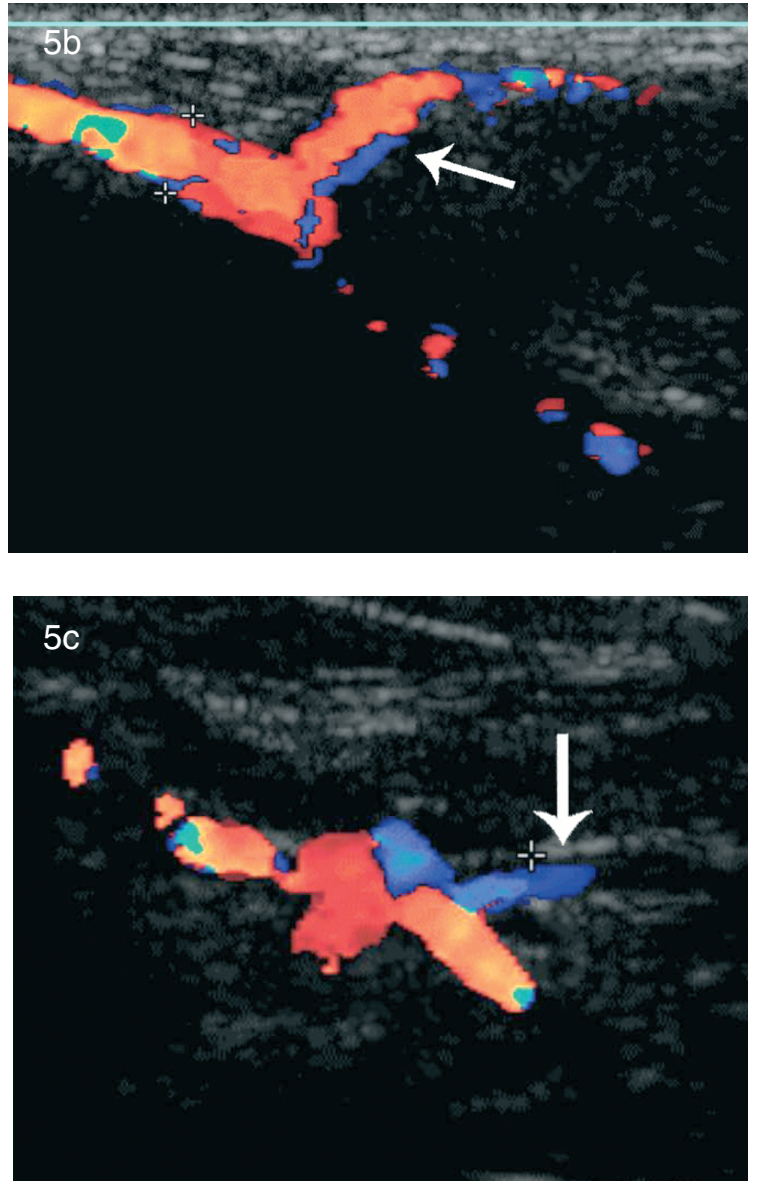

Figura 5 a-c. a) Esquema con la ubicación de la primera arteria intermetatarsiana dorsal, rama terminal de la arteria pedia. b) Ecografía Doppler color, vista longitudinal, de la primera arteria intermetatarsiana dorsal tipo I A (flecha), que efectúa su recorrido por el plano superficial al músculo del primer espacio interóseo dorsal del pie. c) Vista longitudinal, Doppler Color de primera arteria intermetatarsiana dorsal tipo I B (flecha), la cual efectúa su recorrido por el espesor del músculo del primer espacio interóseo dorsal del pie. 

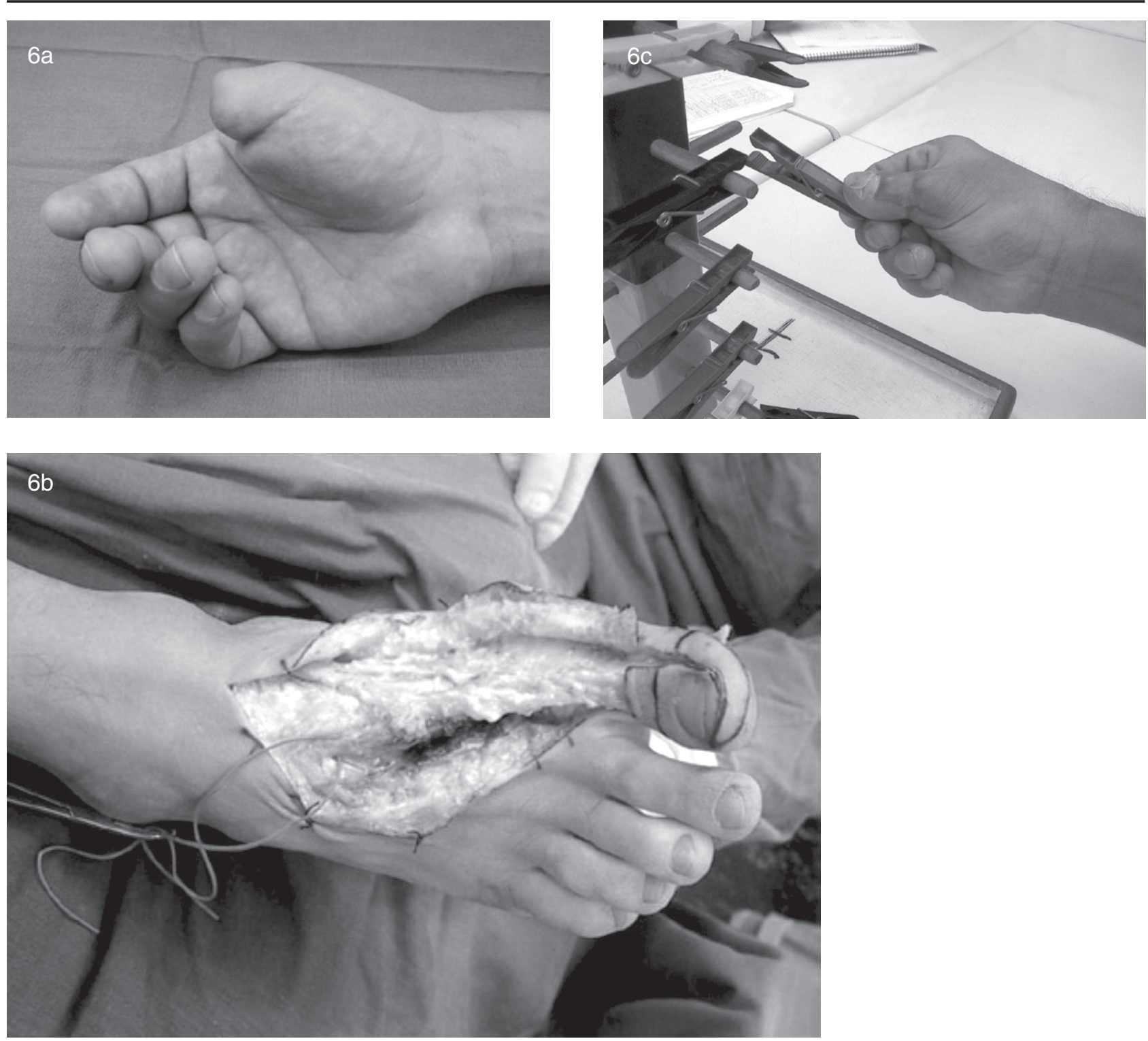

Figura 6 a-c. Transferencia parcial del primer ortejo del pie. a) Paciente de 38 años, con amputación del pulgar derecho. b) Cirugía y disección de transferencia parcial de primer ortejo. c) Control a los cuatro meses, el paciente ha recuperado totalmente la función de pinza de mano.

\section{Contraindicaciones en cirugía de colgajos}

Existe contraindicación absoluta de estas cirugías al demostrarse oclusión arterial y/o venosa. Son contraindicaciones relativas la presencia de calcificaciones de las paredes arteriales, hipoplasias arteriales y variantes anatómicas de recorrido de un vaso, las cuales el cirujano tendrá en cuenta durante el acto quirúrgico, por lo que nuestro estudio y descripción deben ser siempre extremadamente acuciosos.

\section{Complicaciones de cirugías de colgajos}

Se describen algunas complicaciones eventuales de la cirugía de colgajos, que van desde pequeños hematomas y seromas residuales sin mayor importancia, hasta su pérdida total, gene- ralmente provocada por oclusión del pedículo vascular.

Dentro de las posibles complicaciones podemos citar: seromas, hematomas, necrosis cutánea superficial, dehiscencia de la herida operatoria, inadecuada cobertura del defecto, infecciones, pérdida parcial del colgajo y pérdida completa del colgajo.

\section{Conclusiones}

El estudio US Doppler color de alta resolución es una técnica útil para el estudio de trayectos arteriales y venosos, superficiales y profundos, que permite una adecuada evaluación y planificación pre y postoperatoria de cirugía de colgajos, contribuyendo a su éxito. 
Es una técnica de bajo costo que provee información detallada de las características de las paredes, permeabilidad y flujo de un trayecto arterial o venoso. Permite evaluar con certeza el estado y la ubicación del pedículo vascular a utilizar, controlar y efectuar seguimiento postcirugía y detectar en forma precoz las complicaciones.

\section{Agradecimientos}

A los Drs. Manuel Méndez, Alejandro Bifani y Héctor Roco, cirujanos del Hospital del Trabajador, de Santiago, por su apoyo y entrega de valioso material.

\section{Bibliografía}

1. Netter FH. Sistema músculo-esquelético, Tomo VIII, parte 1, Anatomía, fisiología enfermedades metabólicas. Ediciones Científicas y Técnicas S. A., Salvat, Medicina, 1993; pp. 55-91.

2. Serafín R. Atlas of microsurgical composite tissue transplantation, W.B Saunders Company, 1996.

3. Stechen JB, Weiss AP. Reconstruction of traumatic abscence of the thumb by microvascular free tissue transfer from the foot. Hands Clinics, 1992; 8: 17-32.

4. Agur A. Grant's Atlas of Anatomy, 1991; pp. 262: 429-450.

5. Merle M, Dantel G, Loda G. Mano Traumática, Masson, CD Room; 1998; pp. 7-26. 